\title{
Mechanism Development and Position Control of Smart Buoy Robot
}

\author{
Hwi-Geun Park ${ }^{1}$ and Hyun-Sik Kim $\circledast^{2}$ \\ ${ }^{1}$ Graduate Student, Department of Mechanical System Engineering, Tongmyong University, Busan, Korea \\ ${ }^{2}$ Professor, School of Mechanical Engineering, Tongmyong University, Busan, Korea
}

KEY WORDS: Smart buoy robot, Positioning control, Docking and charging, Lighting, Automatic anchoring

\begin{abstract}
There is a gradual increase in the need for energy charging in marine environments because of energy limitations experienced by electric ships and marine robots. Buoys are considered potential energy charging systems, but there are several challenges, which include the need to maintain a fixed position and avoid hazards, dock with ships and robots in order to charge them, be robust to actions by birds, ships, and robots. To solve these problems, this study proposes a smart buoy robot that has multiple thrusters, multiple docking and charging parts, a bird spike, a radar reflector, a light, a camera, and an anchor, and its mechanism is developed. To verify the performance of the smart buoy robot, the position control under disturbance due to wave currents and functional tests such as docking, charging, lighting, and anchoring are performed. Experimental results show that the smart buoy robot can operate under disturbances and is functionally effective. Therefore, the smart buoy robot is suitable as an energy charging system and has potential in realistic applications.
\end{abstract}

\section{Introduction}

In recent years, there have been increasing studies on technologies employed in the Fourth Industrial Revolution, including technologies related to the maritime industry. As a result, there have been extensive development and application of autonomous surface vessels, unmanned surface vessels, and surface/underwater robots (Kwon et al., 2017; Kang et al., 2014; Jeong et al., 2018; Yeu et al., 2019).

In addition, the International Maritime Organization (IMO) has enacted safety regulations on factors that contribute to the destruction of marine environments by vessels, so there is an increased need for the development of electric vessels (Clayton et al., 2000).

However, electric vessels and unmanned surface/underwater robots have finite power supply owing to their limited size. Because of this problem, small electric boats and electric ships may drift on the water when the battery is fully discharged. Currently, in South Korea, the Korea Coast Guard is dispatched to charge the battery of drifting electric boats or ships, or another vessel may tow drifting electric boats or ships to port. However, it takes a long time for the Korea Coast Guard to arrive at the location of the drifting boat or ship. Further, there may be collisions when drifting electric boats or ships encounter other vessels.

In order to solve these problems, there have been studies on the development of marine robots that can harvest marine energy, such as sail drones, wave gliders, and underwater gliders (Man et al., 2020). However, energy harvesting technologies cannot be applied uniformly because the shapes and characteristics of robots are diverse. In addition, energy harvesting technologies generally supply power in proportion to the size of the robot. Because marine robots that harvest energy are limited in their size, this method cannot be considered a realistic solution from an efficiency perspective.

To solve this problem, there is the need for a system that is fixed to a specified position and that can charge batteries. A buoy was considered because it is fixed to a specified position in the ocean. A buoy is tethered to an anchor, so it can maintain its position. Buoys are used for various roles, such as showing a route or informing oncoming traffic about hazardous areas (Kim, 2015). However, anchors that secure buoys to fixed positions may be disconnected owing to inclement weather conditions in the ocean. In such a case, the buoy cannot maintain its specified position and may drift towards shore. Moreover, the different shapes of buoys make it difficult for docking by vessels, which may damage the buoy during docking.

In order to solve these problems, research on marine charging light buoy robots was also conducted in South Korea. However, modularization for maintenance and optimization were not achieved during the design and manufacturing processes. In addition, there was

Received 8 June 2021, revised 2 July 2021, accepted 9 July 2021

Corresponding author Hyun-Sik Kim: +82-51-629-1565, hyunskim@tu.ac.kr

(c) 2021, The Korean Society of Ocean Engineers

This is an open access article distributed under the terms of the creative commons attribution non-commercial license (http://creativecommons.org/licenses/by-nc/4.0) which permits unrestricted non-commercial use, distribution, and reproduction in any medium, provided the original work is properly cited. 
also a problem with respect to waterproofing (Park et al., 2019).

Therefore, in this study, the problem regarding waterproofing was factored in during the design and manufacturing processes, and the modularization of the robot was considered for maintenance. In addition, we proposed the development of a smart buoy robot mechanism that enables the buoy robot to maintain its specified position using underwater motors. Unlike the shapes of existing buoys, the proposed robot has four docking parts and is shaped like the letter $\mathrm{X}$, making it easy for vessels to dock with it.

The International Association of Marine Aids to Navigation and Lighthouse Authorities (IALA) and the Ministry of Oceans and Fisheries (MOF) recommend specific colors and light colors for standard buoys (IALA, 2017). However, because the proposed buoy is a non-standard buoy, we considered an arbitrary color and light color. We differentiated the color by combining the purple color with the yellow color of special aid to navigation, and we used purple light.

Section 2 describes the development of the buoy robot mechanism, and Section 3 focuses on the design of the buoy robot controller. Section 4 explains the experiment and considerations made when verifying the performance of the buoy robot mechanism and proposed controller. Finally, Section 5 summarizes the paper.

\section{Development of Buoy Robot Mechanism}

The operation concept shown in Fig. 1 was first considered for the development of the buoy robot

The body of the robot is formed in the shape of a buoy, and a manipulator is mounted on the robot so it can deliver a cable when a vessel that needs to be charged is docked with the robot. When the robot is moving, the manipulator is folded against the column to minimize the effect of disturbance. The camera is mounted on the robot so that it can check for ships.

The buoy robot was designed based on the operation concept using a three-dimensional (3D) tool called Computer Aided Three dimensional

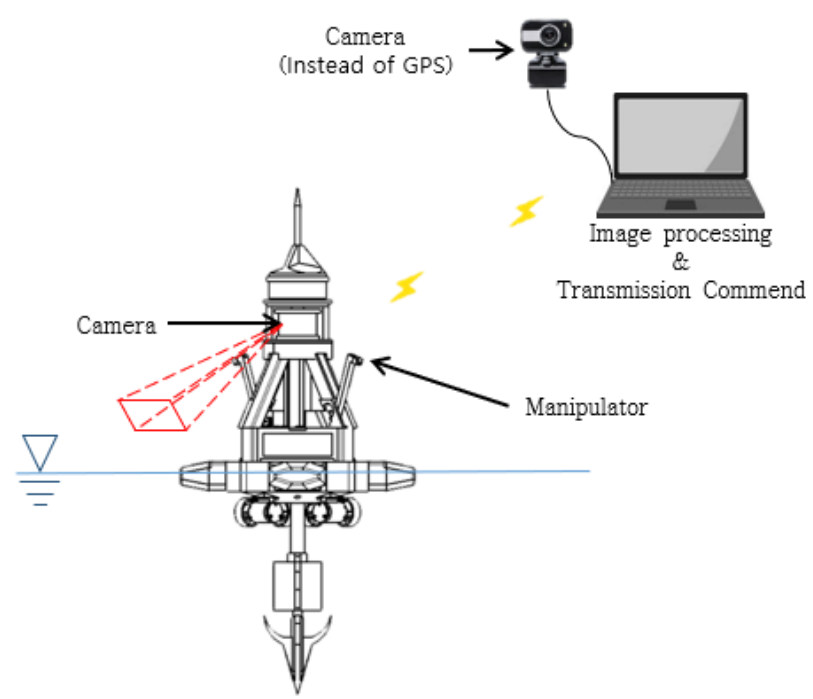

Fig. 1 Diagram of operation concept

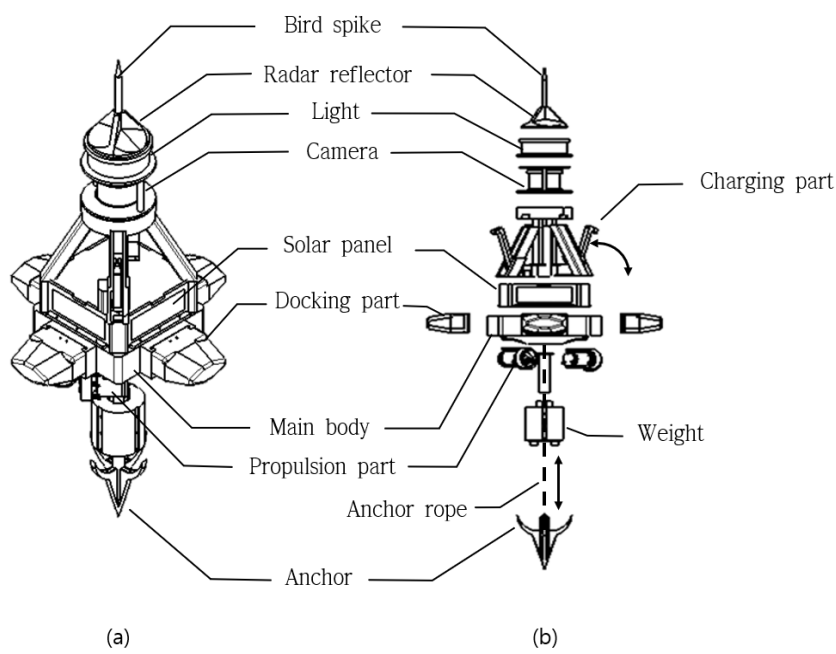

Fig. 2 Mechanism of buoy robot

Interactive Application (CATIA). Fig. 2(a) shows the final design, and Fig. 2(b) illustrates the design that considers modularization, as mentioned previously. Each module was made such that it is easy to disassemble and assemble them. The buoy is made in the shape of the letter $\mathrm{X}$, formed by four docking parts. This shape was considered to allow the bow and stern of a ship to dock with the robot, making it easy to secure the ship to the buoy. In addition, to reduce the maintenance cost, the buoy was designed such that the docking parts can be separated from it and replaced if they are damaged.

Moreover, because bird excrement is acidic, the bird spike performs the function of preventing corrosion, reducing the need for the maintenance of the buoy robot.

The radar reflector is a radio aid to navigation that amplifies and reflects the radar signals. The lighting is a visual aid to navigation that uses light to convey to ships the position guidance and the purpose of the buoy. This system uses purple light.

The camera was installed to visually check the ship that is docked or docking with the buoy robot. The charging part uses the robot arm to deliver the charging cable to the ship that is docking with the buoy robot.

Next, the placement of the solar panel was considered for energy harvesting. The sensor, motor drive, and battery are placed in the main body. The weight was considered to enhance the attitude stability by lowering the buoy robot's center of gravity. The anchor is connected to

Table 1 Functions of buoy robot

\begin{tabular}{lll}
\hline & Rapidity & Propulsion part \\
& Charging & Docking part \\
& & Robot hand \\
Buoy robot & & Bird spike \\
& & Radar reflector \\
& Stability & Light \\
& & Camera \\
& & Anchor \\
\hline
\end{tabular}




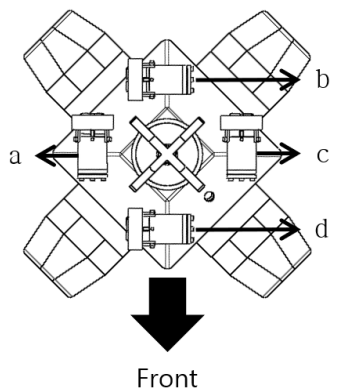

(a)

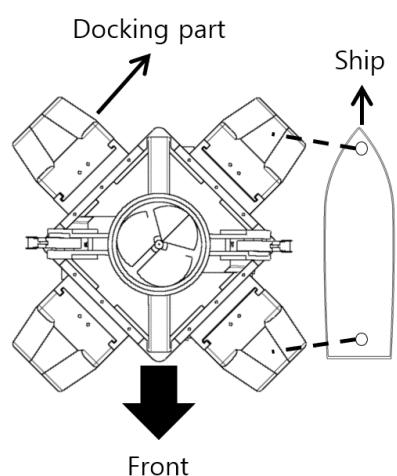

(b)
Fig. 3 Propulsion and docking part

the DC motor placed inside the main body via the anchor rope, and the anchor is designed such that automatic anchoring and retraction are possible. Hence, the buoy robot can be anchored at a specified position, and the anchor is retracted when the buoy robot needs to move. Each function mentioned above is categorized and summarized in Table 1.

Fig. 3(a) shows the composition of the propulsion motor, which is used to control the position and movement of the buoy robot. A total of four motors were used: a, b, c, and d. Motors a and c form a set, and motors $\mathrm{b}$ and $\mathrm{d}$ form another set to control the buoy robot. Because the energy consumption is high when all four motors are used, sets of motors with parallel forces are used. Hence, the position of the buoy robot can be maintained even if one or two motors break down.

The dotted lines in Fig. 3(b) indicate the ropes between the docking parts and the ship. Here, the bow and stern of the ship are secured to two docking parts. As mentioned earlier, there are four docking parts, so it is easy to secure a ship. At most, two ships can dock with the buoy robot simultaneously.

Fig. 4 shows the shape of the completed prototype. The prototype was made as a miniaturized model to make it convenient for

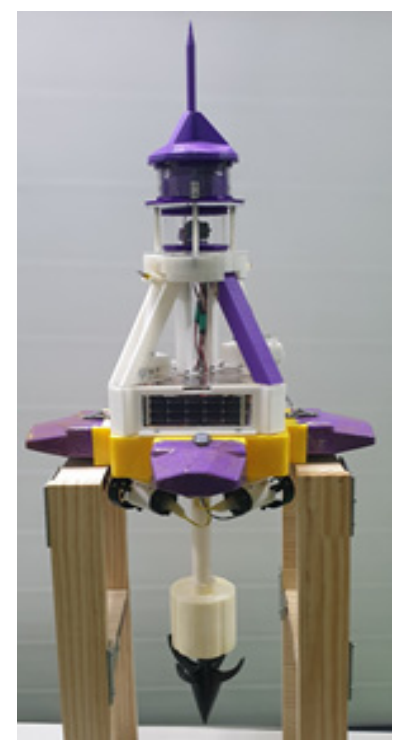

Fig. 4 Prototype of buoy robot
Table 2 Specification of prototype

\begin{tabular}{lrcc}
\hline & Turning radius & degree & 0 \\
Weight (on air) & $\mathrm{kg}$ & 3.5 \\
Payload & $\mathrm{kg}$ & 1.25 \\
& Length over all $(L)$ & $\mathrm{mm}$ & 410 \\
\multirow{3}{*}{ Size } & Moulded brdadth $(B)$ & $\mathrm{mm}$ & 410 \\
& Depth $(D)$ & $\mathrm{mm}$ & 365 \\
Speight $(H)$ & $\mathrm{mm}$ & 490 \\
& Electric propulsion & $\mathrm{m} / \mathrm{s}$ & 0.07 \\
& (Max. speed) & $\mathrm{knot}$ & 0.136 \\
\hline
\end{tabular}

fabrication and experimentation, and the prototype was fabricated using a 3D printer based on 3D modeling. As mentioned previously, yellow and white colors were used for the body of the buoy robot, and purple color was used for the docking part, bird spike, and radar reflector. The part that covers the body of the buoy robot was fabricated using acrylic. Table 2 shows the specifications of the completed robot.

\section{Design of Buoy Robot Controller}

The buoy robot performs positioning control by receiving the error value of the image coordinates using the camera that is connected to the host PC. Fig. 5 shows the flowchart of the control algorithm. First, the heading is controlled using the attitude heading reference system (AHRS). The position is then controlled by using the error value of the current position from the target position on the image coordinates.

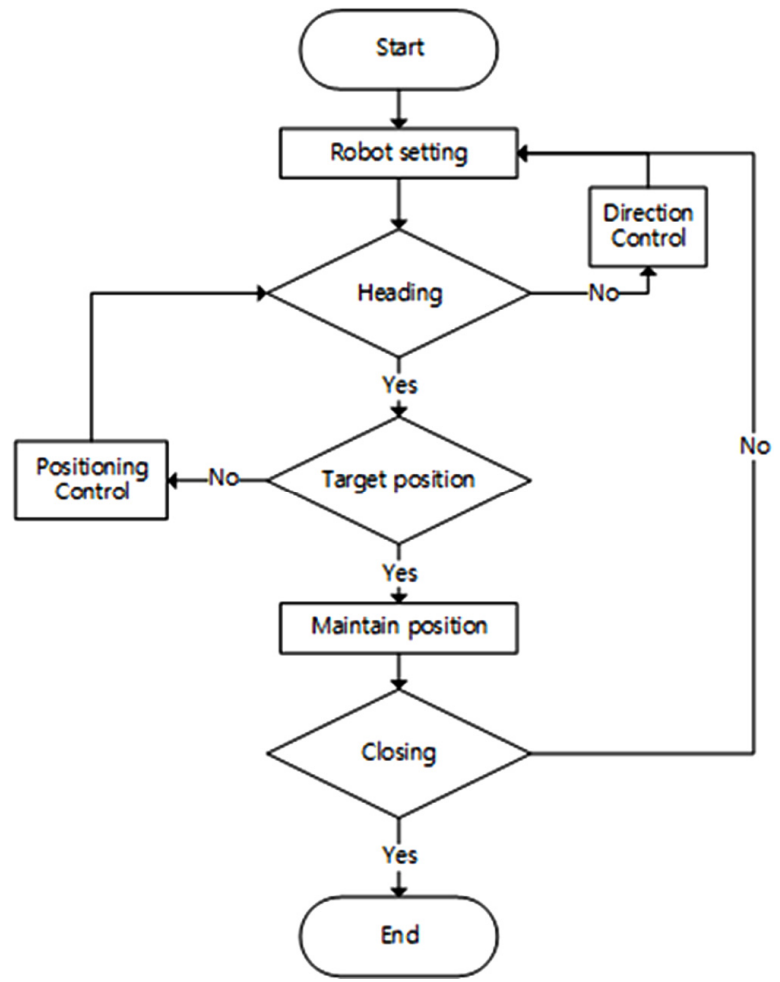

Fig. 5 Flow chart of control algorithm 


\subsection{Position Accuracy, PA}

The PA related to the performance index of the position control is defined by Eq. 1 when the reference position $x_{r}, y_{r}$ is determined. The PA denotes the maximum error position value of the buoy robot.

$$
\begin{aligned}
& r_{i}=\sqrt{\left(x_{i}-x_{r}\right)^{2}+\left(y_{i}-y_{r}\right)^{2}} \\
& P A=\max \left(r_{i}\right)
\end{aligned}
$$

Here, $x_{i}, y_{i}$ is the position value of the buoy robot at the $i$-th sampling time, and $\max ()$ is a function that calculates the maximum value.

\subsection{Current Direction Prediction}

In order to control the position of the buoy robot robustly in the presence of current disturbances, it is necessary to predict the direction of the current. In this study, we selected a method that utilizes the position information to predict the direction of the current. When a current occurs, the buoy is generally pushed in the direction the current flows, and its position information is changed. In order to predict the direction of the current using the change in the position information, Eq. 2 below is considered to first determine the effect of the current. The direction of the current is predicted by using the difference between the target position value and the position value at the moment this equation is satisfied.

$$
r^{2}<\left(x_{i}-x_{r}\right)^{2}+\left(y_{i}-y_{r}\right)^{2}
$$

Here, $r$ is the reference radius, and it is set empirically to determine whether the buoy robot was affected by the current (Park, 2021).

In Fig. 6, the solid lines intersecting at the center of the buoy robot are the $\mathrm{x}$ and $\mathrm{y}$ axes of the image reference coordinate system. The dotted arrows indicate the moving direction for each set of thrusters, as explained in Fig. 3.

Here, the thrusters can propel the buoy robot uniformly at $45^{\circ}$ with reference to the image reference coordinate system. Therefore, the area

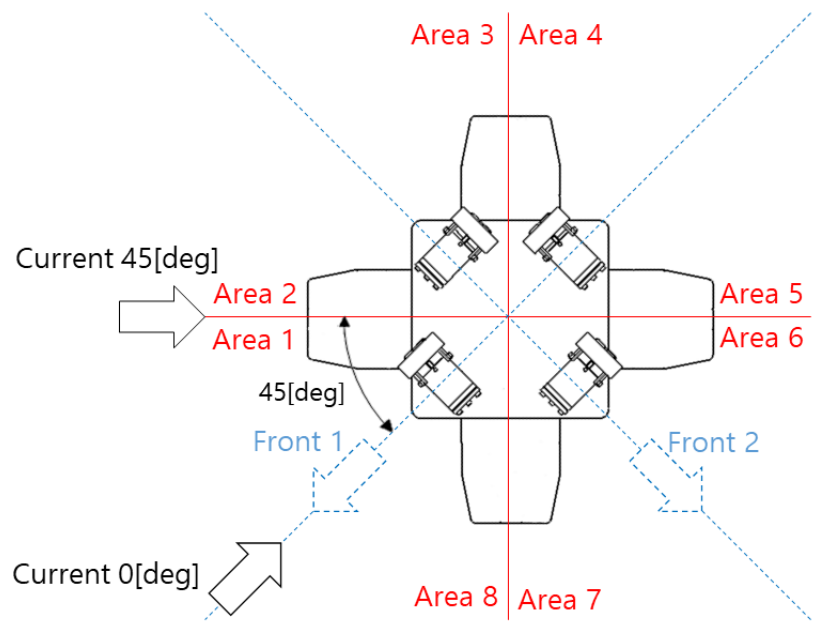

Fig. 6 Anaysis of current directions and areas

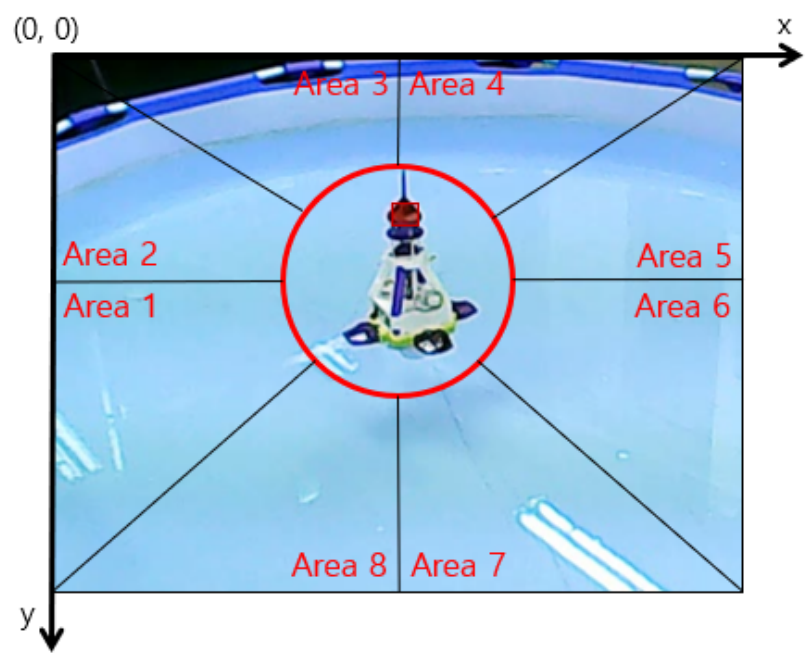

Fig. 7 Coordinate system of camera

of the image reference coordinate system can be subdivided using the dotted arrows. The dotted lines formed using the direction of motion are composed of straight-line regions. They can be divided into eight areas using the straight-line regions and the image reference coordinate system.

Because each of the eight regions has an area of $45^{\circ}$, the direction of the currents generated in all regions is equivalent to two cases--the direction is a minimum of $0^{\circ}$ and a maximum of $45^{\circ}$. The solid arrow denotes the arrow for the direction of the current mentioned.

Fig. 7 shows the actual display of the camera that was installed for the experiment as a substitute for GPS. Of the three red, green, blue (RGB) colors, the red color is tracked for ease of implementation. With regard to acquiring the buoy robot's position information, the red color is tracked to simplify camera image processing. The radar reflector was set to red color, and the radius of the circle related to Eq. (2) was formed based on the radar reflector. Using this setup, it is possible to know the region in which the buoy robot is located.

Fig. 8 shows a control block diagram. The P-Controller, which is a proportional controller using an error, was considered. In addition, the distributor is used to distribute the control values to the motors $M_{1}$, $M_{2}, M_{3}, M_{4}$ which control $P_{x}, P_{y}$. Here, $x_{r}, y_{r}$ is the target position and denotes $(97,42) . e_{x}$ denotes the x-coordinate error, and $e_{y}$ denotes the y-coordinate error. $x_{i}, y_{i}$ indicates the current $\mathrm{x}, \mathrm{y}$ coordinates values. The P-Controller derives and using the $\mathrm{x}$ and $\mathrm{y}$ error values, respectively, and control values are input into each motor $\left(M_{1}, M_{2}\right.$, $M_{3}, M_{4}$ ) through the distributor.

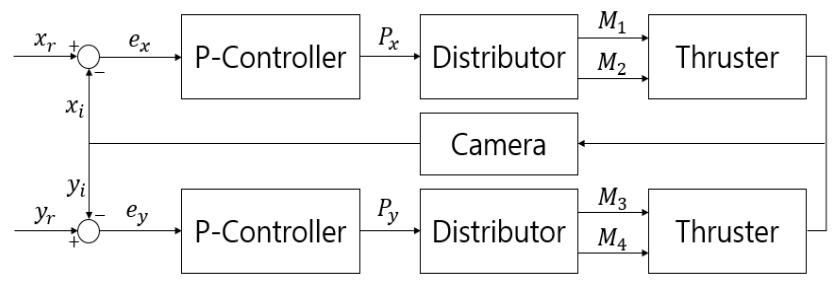

Fig. 8 Block diagram of position control system 


\section{Experimental Results}

A test evaluation was performed to verify the performance of the developed robot. First, functional tests were performed to verify the mechanism of the buoy robot. The test evaluation was composed of four categories. Propulsion (T1) is a test evaluation category that is related to the propulsion of the robot, and mechanism (T2) is a category for the robot's lighting, charging, and anchoring functions.

Communication (T3) is a category that determines whether data transmission and control are possible by performing communication between the robot and the host PC to control the robot. Positioning control (T4) is a category that checks whether the control method proposed in Section 3 has been applied to the robot to enable the position control.

The results of the requirements analysis are mobility (R1), manipulability (R2), observability (R3), stability (R4), and maintainability (R5). The functional categories are the forward/reverse rotation function of the underwater motor (F1), lighting function (F2), docking and charging function (F3), automatic anchoring and retraction function $(\mathrm{F} 4)$, camera function (F5), attitude restoration function (F6), modularization function (F7), and program download function (F8). H/W and S/W categories are components of the $\mathrm{H} / \mathrm{W}$ and $\mathrm{S} / \mathrm{W}$ family tree. Table 3 shows the test evaluation results that determine whether each category maintains traceability.

Fig. 9 shows that the (a) docking and charging function, (b) lighting function, and (c) automatic anchoring function are working properly.

The position control experiments were conducted for three cases (when current was not generated, when the current was generated from the oncoming direction, and when the current was generated from the $45^{\circ}$ direction), and the results were compared.

Fig. 10 shows the experimental environment, and a water tank was used for the indoor experiment. In addition, a camera was used in place of the GPS, and images were processed to distinguish and track the red color using the RGB.

Table 3 Traceability

\begin{tabular}{|c|c|c|c|c|c|}
\hline $\begin{array}{c}\text { Requir- } \\
\text { ement }\end{array}$ & Function & $\begin{array}{c}\mathrm{H} / \mathrm{W} \\
\text { component }\end{array}$ & $\begin{array}{c}\mathrm{S} / \mathrm{W} \\
\text { component }\end{array}$ & $\begin{array}{c}\text { Test \& } \\
\text { Evaluation }\end{array}$ & Result \\
\hline $\mathrm{R} 1$ & F1 & $\begin{array}{l}\mathrm{H} 2, \mathrm{H} 5, \\
\mathrm{H} 6\end{array}$ & $\mathrm{~S} 1, \mathrm{~S} 4$ & $\mathrm{~T} 1, \mathrm{~T} 4$ & $\bigcirc$ \\
\hline \multirow{3}{*}{$\mathrm{R} 2$} & $\mathrm{~F} 2$ & $\begin{array}{l}\text { H33, H51, } \\
\text { H71 }\end{array}$ & S21 & $\mathrm{T} 2$ & $\bigcirc$ \\
\hline & F3 & $\begin{array}{l}\text { H131, H2, } \\
\text { H31, H4, } \\
\text { H5, H6 }\end{array}$ & $\begin{array}{l}\text { S1, S22, } \\
\text { S3, S4 }\end{array}$ & $\begin{array}{l}\text { T1, T2, T3, } \\
\text { T4 }\end{array}$ & $\bigcirc$ \\
\hline & $\mathrm{F} 4$ & H32, H5 & $\mathrm{S} 23, \mathrm{~S} 3$ & $\mathrm{~T} 2, \mathrm{~T} 4$ & $\bigcirc$ \\
\hline $\mathrm{R} 3$ & F5 & $\begin{array}{l}\mathrm{H} 2, \mathrm{H} 42, \\
\mathrm{H} 5, \mathrm{H} 6, \\
\text { H71 }\end{array}$ & $\begin{array}{l}\text { S1, S24, } \\
\text { S3, S4 }\end{array}$ & $\begin{array}{l}\text { T1, T2, T3, } \\
\text { T4 }\end{array}$ & $\bigcirc$ \\
\hline $\mathrm{R} 4$ & F6 & H13 & - & & $\bigcirc$ \\
\hline \multirow{2}{*}{ R5 } & F7 & $\mathrm{H} 1$ & - & & 0 \\
\hline & F8 & $\mathrm{H} 7$ & S4 & & $\bigcirc$ \\
\hline
\end{tabular}

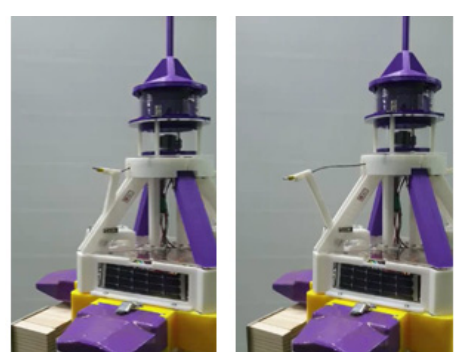

(a) Docking and charging function

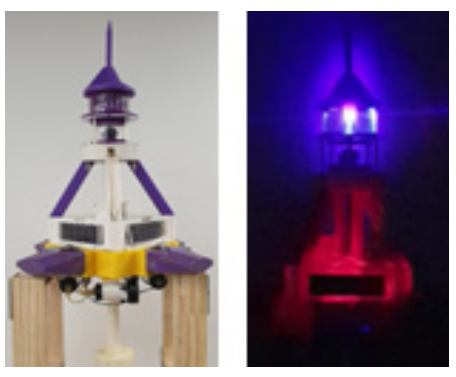

(b) Light function

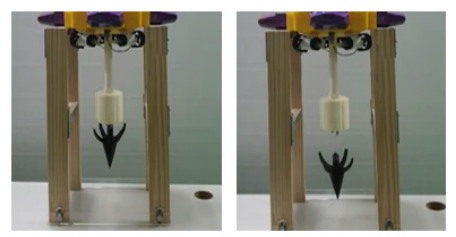

(c) Automatic anchoring funtion

Fig. 9 Functional tests of buoy robot

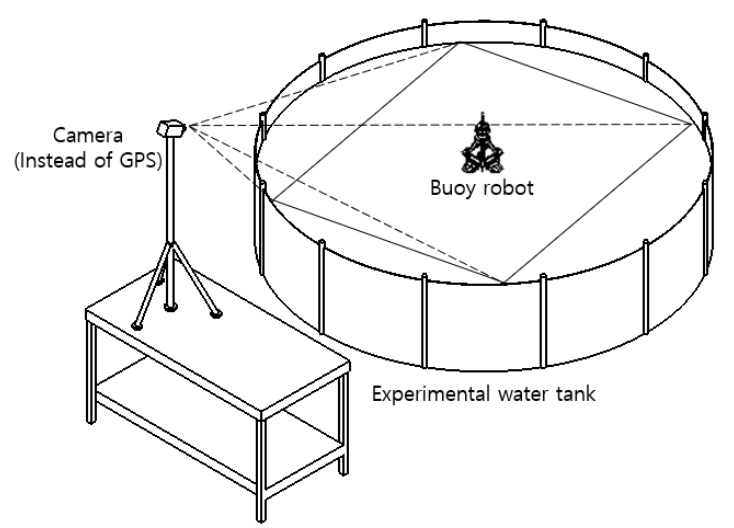

Fig. 10 Experimental enviroment

Figs. 11-13 illustrate the test evaluation scenarios. Here, the large arrow indicates the front, and the five small arrows represent the

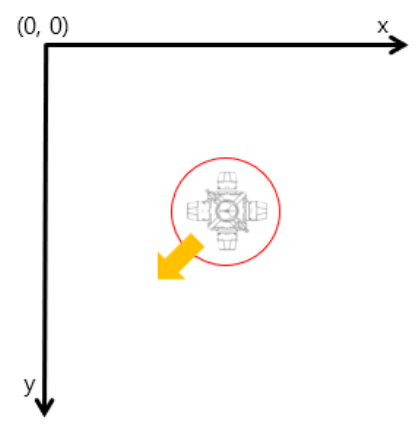

Fig. 11 Scenario for position control (no disturbance) 


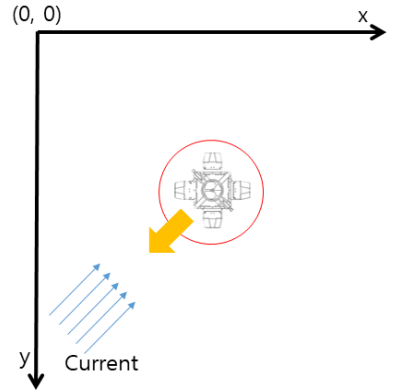

Fig. 12 Scenario for position control $\left(0^{\circ}\right.$ disturbance $)$

current. Fig. 11 shows the scenario where position control is performed at the target position when there is no current disturbance.

Fig. 12 shows the scenario where position control is performed at the target position when there is a current disturbance in the $0^{\circ}$ direction.

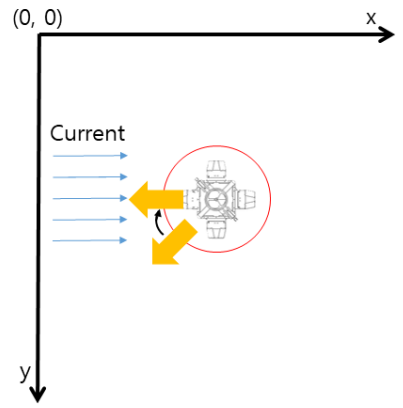

Fig. 13 Scenario for position control $\left(45^{\circ}\right)$
Fig. 13 shows the scenario where position control is performed at the target position when there is a current disturbance in the $45^{\circ}$ direction.

The experiments were conducted for each scenario mentioned above after empirically setting the radius of the discriminant-related circle to 10. The results of the experiments are as follows.

The maximum X, Y coordinates of the camera images are (320, 240 ), and the basic unit of the coordinates is measured to be about 1 $\mathrm{cm}$. The experimental results are shown on the area where the $\mathrm{X}$-axis ranges from 50 to 140 and the $\mathrm{Y}$-axis ranges from 20 to 65 . The target position is $(97,42)$. In the legend, the diamond mark denotes the target position, and small circles denote the sampling positions of the buoy robot. In addition, the dotted line represents the PA-related circle, and the solid line represents the discriminant-related circle.

In Fig. 14, the PA is $7.1 \mathrm{~cm}$, and there is no current disturbance. Therefore, position control was performed inside the discriminantrelated circle. Because small circles are densely populated, it can be seen that position control is well performed.

In Fig. 15, the current was generated from the $0^{\circ}$ direction. Because a large number of small circles are distributed in the upper right region of the graph, it can be seen that the current was generated in the direction of $(70,60)$. Even though a few small circles were pushed outside the discriminant-related circle owing to the effect of the current, position control was performed without performing direction control because the current was generated from the oncoming direction. Because small circles are distributed in similar positions, it can be seen that position control is well performed. The PA is $10.8 \mathrm{~cm}$,

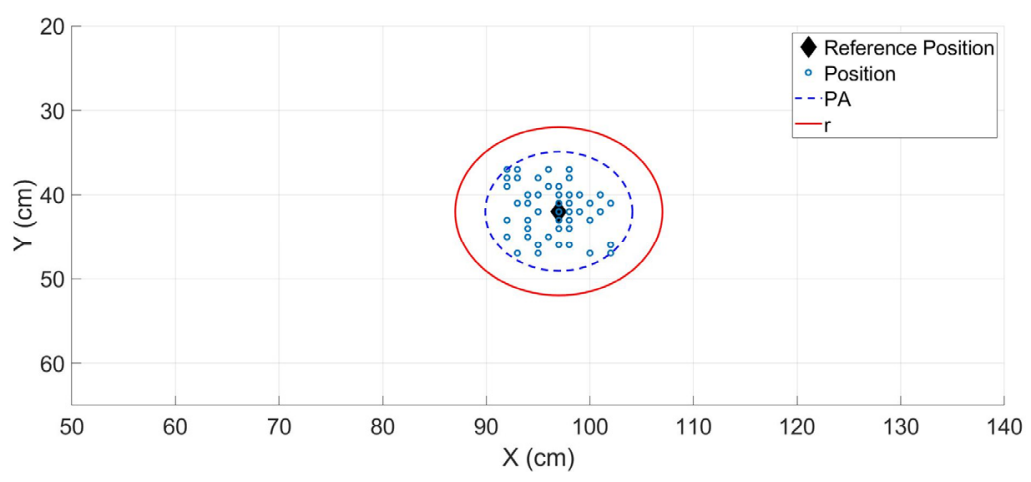

Fig. 14 Performance of position control (no disturbance)

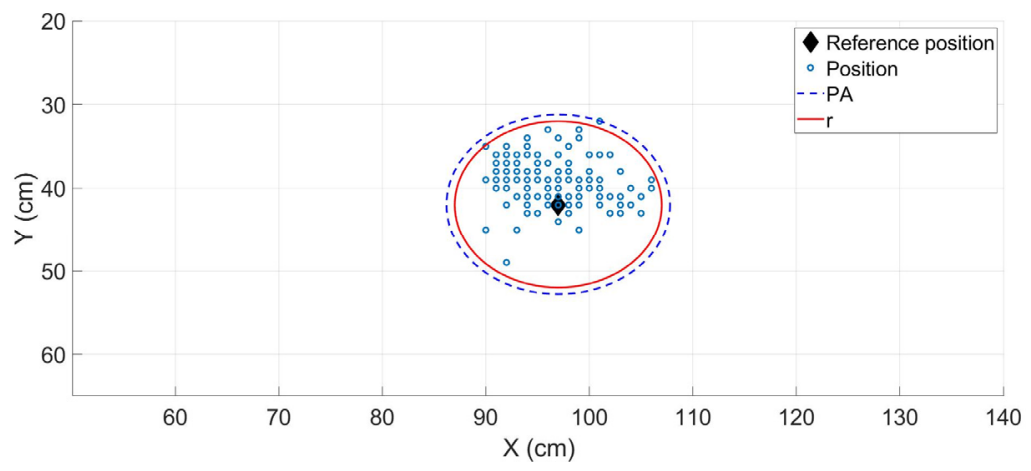

Fig. 15 Performance of position control $\left(0^{\circ}\right.$ disturbance $)$ 


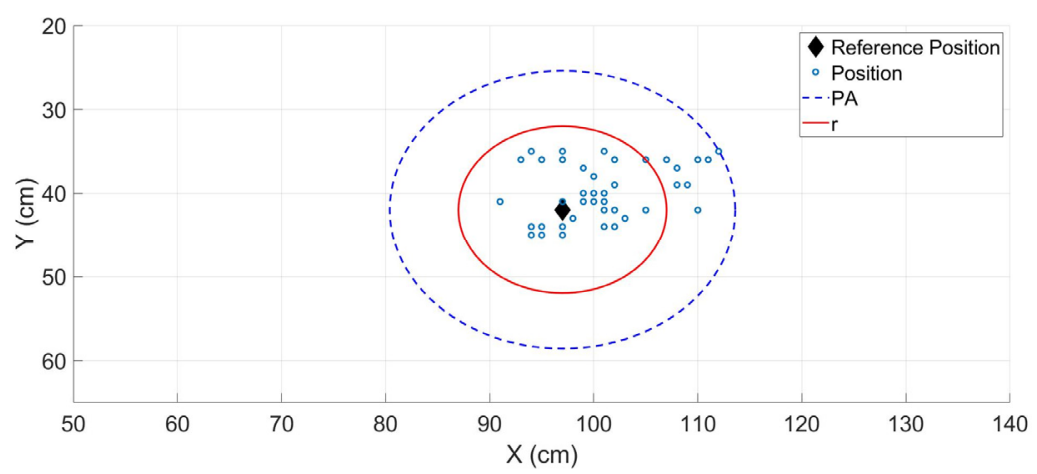

Fig. 16 Performance of position control $\left(45^{\circ}\right.$ disturbance)

Table 4 Experimental results

\begin{tabular}{cccc}
\hline Scenario & $\begin{array}{c}\text { No } \\
\text { disturbance }\end{array}$ & $\begin{array}{c}0 \text { - } \\
\text { disturbance }\end{array}$ & $\begin{array}{c}\text { 45-degree } \\
\text { disturbance }\end{array}$ \\
\hline Heading initial value & $0.0^{\circ}$ & $0.0^{\circ}$ & $0.0^{\circ}$ \\
Heading change value & $\times$ & $\times$ & $45.0^{\circ}$ \\
Disturbance & $\times$ & $\bigcirc$ & $\bigcirc$ \\
PA & $7.1 \mathrm{~cm}$ & $10.8 \mathrm{~cm}$ & $16.6 \mathrm{~cm}$ \\
$r$ & $10.0 \mathrm{~cm}$ & $10.0 \mathrm{~cm}$ & $10.0 \mathrm{~cm}$ \\
\hline
\end{tabular}

so the PA value is increased by $3.7 \mathrm{~cm}$ compared to the case when there was no current.

In Fig. 16, the current was generated from the $45^{\circ}$ direction. Because many of the small circles are distributed on the right side of the graph, it can be seen that the current was generated in the direction of (70, 45). The small circles were pushed out of the discriminant-related circle owing to the effect of the current. Because the current was generated from the direction that is not directly in front of it, direction control was first performed, followed by position control. Because the position control was performed after the direction control, it can be seen that the position control has increased. In addition, the PA is 16.6 $\mathrm{cm}$. Compared to the case when there was no current, it can be seen that the PA value is increased by about $9.5 \mathrm{~cm}$.

The experimental results for the three types of scenarios are summarized in Table 4. Direction control was performed to change the direction from $0^{\circ}$ to $45^{\circ}$ only for the scenario where the current was generated from the $45^{\circ}$ direction. In addition, it can be seen that the error radius for each scenario is increased owing to the current.

\section{Conclusion}

This study investigated the mechanism and position control of a new smart buoy robot that considers the shape, colors, and light such that they are different from those of existing buoys.

The developed smart buoy robot is shaped like the letter X, making it easy for docking, and this is different from existing buoys. A purple light was used, which is not in conflict with the IALA recommendations, and a yellow color was used to provide special aid for navigation purposes, and the buoy was made to have the color purple. Maintenance was considered through modularization, and various mechanisms, such as docking, charging, automatic anchoring, and retraction, can be verified from the perspective of functionality.

In addition, the proposed position controller used the P-Controller, and three experiment scenarios were modeled. Based on the experiment results, it was confirmed that the proposed position controller has outstanding performance. When the current was generated from the $45^{\circ}$ direction, the buoy robot was pushed out of the reference radius. Therefore, direction control is performed, followed by position control, using the radius of the current direction discriminant-related circle. As a result, the buoy robot was pushed out by the current during the direction control process. However, after the direction control, it was seen that the buoy robot overcomes the current head-on.

This study has established a foundation for domestic research on smart buoy robots. However, there was no study on energy harvesting technologies and their efficiency, which have potential for application to smart buoy robots. In the future, we plan to continue our research on the efficiency of marine energy harvesting techniques that are suitable for smart buoy robots.

\section{References}

Kwon, Y.J., Kang, G.M., \& Park, S.H. (2017). The Fourth Industrial Revolution and Marine Technology. Journal of Innovation Studies, 12(2), 203-222. http://dx.doi.org/10.46251/INNOS. 2017.05.12.2. 203

Kang, H.J., Man, D.W., \& Kim, H.S. (2014). Development of Mechanism for Micro Surface Robot with Rotating Sonar-Beam. Journal of Korean Institude of Intelligent Systems, 24(4), 437442. http://dx.doi.org/10.5391/JKIIS.2014.24.4.437

Jeong, J.S., Sa, Y.M., \& Kim, H.S. (2018). Development of Autonomous Surface Robot for Marine Fire Safety. Journal of Ocean Engineering and Technology, 32(2), 138-142. https://doi. org/10.26748/KSOE. 2018.4.32.2.138

Yeu, T., Choi, H.T., Lee, Y., Chae, J., Lee, Y., Kim, S.S., ... \& Lee, T.H. (2019). Development of Robot Platform for Autonomous Underwater Intervention. The Korean Society of Ocean Engineers, 33(2), 168-177. https://doi.org/10.26748/ 
KSOE.2019.021

Clayton, D.H., Sudhoff, S.D. , \& Grater, G.F. (2000). Electric Ship Drive and Power System. Proceedings of Conference Record of the 2000 Twenty-Fourth International Power Modulator Symposium, 85-88. https://doi:10.1109/MODSYM.2000.896171.

Man, D.W., Cho, G., \& Kim, H.S. (2020). Comparative Study on Keel Effects of Catamaran-Type Sail Drone. ICIC Express Letters, Part B: Applications, 11(3), 261-266. https://doi.org/10.24507/ icicelb.11.03.261

Kim, H.S. (2015). Development of Buoy-based Autonomous Surface Robot-kit. Journal of Ocean Engineering and Technology, 29(3). 249-254. http://dx.doi.org/10.5574/KSOE.2015.29.3.249

Park, H.G., Man, D.W., Jo, Y.J., \& Kim, H.S. (2019). Lighting Buoy Type Marine Charging Robot Base on Marine Energy Harvesting. Proceedings of KIIEE (Busan • Ulsan • Kyungnam
Branch) Annual Conference, 59-62.

International Association of Marine Aids to Navigation and Lighthouse Authorities (IALA). (2017). R1001-The IALA Maritime Buoyage System. Retrieved from https://www.ialaaism.org/product/r1001-iala-maritime-buoyage-system/

Park, H.G. (2021). Study on Development and Position Control of Smart Buoy Robot (Master's thesis). University of Tongmyong, Busan, Korea.

\section{Author ORCIDs}

$\begin{array}{ll}\text { Author name } & \text { ORCID } \\ \text { Park, Hwi-Geun } & 0000-0003-3139-2337 \\ \text { Kim, Hyun-Sik } & 0000-0003-4821-9784\end{array}$

